\title{
The Role of Resistin Level and Genetic Study for Patients with Hypercholesterolemia HJ Hidayet ${ }^{1}$, LA Baker ${ }^{2}$
}

\begin{abstract}
Objective: The study aimed to investigate the role and level of resistin and correlation some biochemical parameters (ox-LDL, Hcy, LDL-C, TC, HDL, BMI and lipid peroxidation MDA), Antioxidant (GSH, A, $\mathrm{C}, \mathrm{E})$, also we studied familial hypercholesterolemia $(\mathrm{FH})$ to investigate the effects of MTHFR gene mutation.
\end{abstract}

Material and methods: 64 patients (33females and 31males) who attend Rizgary teaching hospital, Erbil, Iraq, between November 2014 to March 2015, the study included biochemistry parameter analysis and genetic study MTHFR gene (exon4) for females with ( hypercholesterolemia and FH).

Results: hypercholesterolemia and FH are cause of increase in (LDL-C, HDL-C, ox-LDL, Hcy, MDA( levels and the results show increase in resistin level and correlation with BMI, as well as the results show decrease in antioxidants levels. The genetic study for MTHFR gene the results show mutations in sequence of (exon4) for the gene which show (Pro (777) deletion (C) and Glu (784) deletion (A) for female patient with hypercholesterolemia) and (Lys (10844) deletion (A) and Asp (10877) deletion (G) for female with FH which leading frame shift or protein truncation).

Conclusion: Hypercholesterolemia and FH are cause of increase in (resistin, LDL-C, HDL-C, ox-LDL, Hcy, MDA) levels and correlation with BMI, as well as decrease in antioxidants levels. Also MTHFR gene mutation (exon4) has an effect of patients with (hypercholesterolemia and FH).

Keywords: Antioxidant, familial hypercholesterolemia, methylenetetrahydrofolate reductase (MTHFR), resistin

From: ${ }^{1}$ College of Education, University of Salahaddin, Erbil, Iraq and ${ }^{2}$ College of Education for Pure Science, University of Mosul, Iraq.

Correspondence: Dr L Baker, College of Education for Pure Science, University of Mosul, Iraq.

E-mail: 1olo1_978@yahoo.com 


\section{INTRODUCTION}

Hypercholesterolemia is clinically characterized by an increase of the total and low-density lipoprotein (LDL) cholesterol in plasma. It represents a high risk for the development of atherosclerosis (1) were also free radicals play a significant role (2) because they are able to oxidatively damage different molecules. One of the most examined free radical damages is an oxidative damage to lipids in the process of lipoperoxidation. Increased lipid peroxidation has been identified as a key mechanism for the development of atherosclerosis by \{Harrison et al.2003] (3). According to the original oxidative hypothesis of atherosclerosis, oxidative modification of plasma lipoproteins migrated in the subendothelium exerts pro-inflammatory activities and is the necessary condition for the development of atheroma and its complication (4)

Cholesterol is essential for the body, specifically for hormone synthesis, fat digestion, and formation of cell membranes (5). However, large amounts of cholesterol in the bloodstream lead tomyocardial infarction, stroke, ischemic injury, and organ failure (6).

Serum resistin was positively correlated with changes of BMI and body adipose mass. Circulating resistin levels increase with age, probably reflecting the increase in the body fat content. With human obesity elevated serum resistin levels were observed when compared with humans in lean condition. Resistin is involved in the proliferation of adiposities and angiogenesis (7). FH is a genetic alteration of lipoprotein metabolism caused by defects in the low density lipoprotein receptor (LDLR) High LDL levels, secondary to the LDLR homozygous defect, are associated to significant increase of oxidized LDL (ox-LDL), which removed from circulation lead to massive lipid accumulation, foam cell formation in endothelial wall, often tendom xanthomas (TX) and corneal arcus (8). The generation of free radicals and a subsequent increase in oxidative stress is a by-product of an inflammatory environment $(9,10)$. There are several enzymatic and nonenzymatic antioxidant defense systems acting against the harmful effects of 
these reactive oxygen species. Under normal circumstances, there is a balance between the oxidants and antioxidants. However, excessive production of the reactive oxygen species or decreased antioxidant activity causes an oxidative stress (11). The level of GSH in the plasma is likely to be more reflective of tissue intracellular GSH status than the more commonly and more easily measure red blood cell or whole blood GSH levels because red blood cells are normally net producers of GSH. GSH is involved in the intracellular metabolism of vitamin B12. Adequate GSH levels are needed to avoid B12 deficiency and insufficient methylcobalamin to support methionine synthase in the methylation cycle. Normally oxidised GSH (GSSG) is recycled back to reduced GSH by GSH reductase which requires B2. If GSSG is elevated above normal range, this represents oxidative stress. Homocysteine is an amino acid associated with atherosclerosis that can become elevated when there is need for folate, vitamin B6, and/or vitamin B12. Excess homocysteine levels have been correlated with many cardiovascular disorders (12).

Familial hypercholesterolemia $(\mathrm{FH})$ is an autosomal dominant disorder characterized by primary hypercholesterolemia and premature coronary artery disease (CAD). However, the development of CAD in FH shows considerable inter individual variations. Elevated levels of plasma homocysteine have been recognized as independent risk factors for CAD (13).

MTHFR is critical enzyme both folate and homocysteine metabolism, it first achieved medical recognition in severe deficiency of MTHFR in patient with homocysteine in plasma and urine (14). The 5, 10- Methylenetetrahydrofolate reductase (MTHFR) gene is located on short arm (p) of the chromosome 1 at (1p36.3). MTHFR gene spans a 2.2Kb length with 11 exons and 10 introns (15) ranging in size from 103 base pairs (bp) to $432 \mathrm{bp}$, is approximately $2.2 \mathrm{~kb}$. Several mutations in the MTHFR gene have been identified, but most are rare and associated with severe enzymatic deficiency. However, in contrast with these rarities, two common thermolabile single-nucleotide polymorphisms (SNPs) in the MTHFR gene (C677T and A1298C) deserve 
special mention in Chronic Myeloid Leukemia susceptibility because they result in a decrease in MTHFR activity, and its possible consequent effects mentioned above (16). In humans, the majors products of the MTHFR gene is catalytically active 77-kilodalton protein, although a smaller isoform of approximately protein, although a smaller isoform of approximately 70 kilodaltons have been observed in some tissue $(15,17,18)$.

\section{MATERIAL AND METHODS}

We enrolled 64 consecutive patients (33 female) and (31 males) who attend Rizgary teaching hospital, the province of Erbil, Iraq, between November 2014-march2015 and the intensive care cardiac samples were suffer from hypercholesterolemia and $\mathrm{FH}$ disease and they were aged between 25-50 years, were divided in two groups hypercholesterolemia in blood and FH.

Control groups: 80 samples fasten from healthy people (40female 40 male) of the same age groups.

\section{Blood collection and (biochemistry and genetic study) analysis}

Blood samples $(5 \mathrm{ml})$ were collected, fasting blood sample were divided in two parts, the first part used to analyze (LDL-C,HDL-C,TC) commercial diagnostic kits from (BDH) company, serum samples collected for estimation were frozen at $\left(-80{ }^{\circ} \mathrm{C}\right)$ for estimation (resistin, ox-LDL and Hcy) were obtained from MyBiosource company ,USA depend on ELISA. The MDA level in the serum of groups were examined using uchiyama and Mihara methods (19) the method is based on the production of pink company producing maximum absorbance at $535 \mathrm{~nm}$ as a result of thioybarbutixic acid's reaction with MDA, the GSH level was examined using the Ellman's method(20) antioxidant (A,E,C) vitamins were determined by manual methods asin case and control groups, vitamin E depending on Emmerie-Engel reaction (21), vitamin C by using 2,4- 
dinitrophenyl hydrazine (DNPH) method (22), vitamin A determination by using methods which depending on By breaking down the vitamin A by UV rays, and taking the absorbance at the wavelength $(327 \mathrm{~nm})(23,24)$.

The second part from the blood using to identify mutations in the gene responsible for enzyme methylenetetrahydrofolate reductase (MTHFR) Genomic deoxyribonucleic was purified from peripheral white blood cells two females with hypercholesterolemia and $\mathrm{FH}$, measure the concentration and purity DNA by using (Roche, Germany) kit, Quantification and qualification of DNA concentration were performed using a spectrophotometer Nano drop (25). And its amplifications were performed by polymerase chain reaction. Analysis for MTHFR gene exon 4 performed using primers. table1. Using the following PCR thermal program initial denaturation at $95 \mathrm{C}^{\circ}$ for 5 minutes, followed by 30 cycles for denaturation at 30 seconds, annealing at $59 \mathrm{C}^{\circ}$ for exone 15 for 30 seconds and elongation at $72 \mathrm{C}^{\circ}$ for 30 seconds. After the last cycle a final extention $a t 72 \mathrm{C}^{\circ}$ for minutes was performed. The result ant PCR products were; separated and visualized a 2\%agarose gel stained with ethidome bromide Fig 3. DNA sequencing of PCRamplified product was carried out bi-directionally (Sambrook and Russell) method (26).

\section{Statistical analysis}

The data are expressed as mean values with stander deviation (SD) for variable with normal distribution. Statistical differences were computer by using the students test. Statistical analysis were performed with SPSS software (Version 13.0) in significance statistical. 


\section{RESULTS}

The results show table(2) significant decrease in resistin level for the male group with hypercholesterolemia at $\mathrm{p}<0.05$ but no significant difference for male with $\mathrm{FH}$ when compared with control group, Other side the results show significant increase in resistin level in hypercholesterolemia at $\mathrm{p}<0.000$ and $\mathrm{FH}$ at $\mathrm{p}<0.01$ when compared with control group. The results show high signification at $p<0.01$ when compare between males and females for the same group (hypercholesterolemia and FH). Also, the results show increased in BMI level in females at $(\mathrm{p}<0.000, \mathrm{p}<0.001)$ and males at $(\mathrm{p}<0.000, \mathrm{p}<0.001)$ patients with (hypercholesterolemia and FH) when compared with control group and the results show significant increase at $p<0.01$ when compared female and male with hypercholesterolemia but no significant difference between male and female with FH. On the other hand the results explained significant increase in ox-LDL levels for male at $\mathrm{p}<0.000$ and female at $\mathrm{p}<0.001$ with hypercholesterolemia when compared with control group. The results show the patient male at $\mathrm{p}<0.05$ and female at $\mathrm{p}<0.05$ with $\mathrm{FH}$ signification decrease in ox-LDL-C, while the results explained no significant difference between male and female with hypercholesterolemia FH respectively.

On the other hand the result show significant increase in LDL-C at $\mathrm{p}<0.05$ level for male patient with hypercholesterolemia and female with $\mathrm{FH}$ at $\mathrm{p}<0.01$ when compared with control groups and no significant decrease in male with $\mathrm{FH}$, and the results show significant increase at $\mathrm{p}<0.05$ for female with $\mathrm{FH}$ when compared with male with $\mathrm{FH}$.the results indicated significant decrease in HDL-C level for patient at $\mathrm{p}<0.01$ (females and males) with hypercholesterolemia and significant decrease at $\mathrm{p}<0.05$ for male and female with $\mathrm{FH}$ when compare with control group and the results show highly significant HDL-C level for females with hypercholesterolemia compare with male and significant increase in females with FH when compared with male. The 
results show significant increase for male at $\mathrm{p}<0.05$, female at $\mathrm{p}<0.01$ patients with hypercholesterolemia and male at $\mathrm{p}<0.001$, female at $\mathrm{p}<0.000$ patients with FH in TC level

The results show in table (3) highly significant at $\mathrm{p}<0.000$ in lipid peroxidation in MDA level in (female and male) patients with hypercholesterolemia and FH when compared with control group and no signification difference between male and female with hypercholesterolemia, also the results explained significant increase at $\mathrm{p}<0.05$ in MDA level for female (FH) compared with male (FH). The results explained significant decrease at $\mathrm{p}<0.000$ in GSH in all male patients with hypercholesterolemia and $\mathrm{FH}$ as well as the results show significant decrease for female patients with hypercholesterolemia at $\mathrm{p}<0.001$ and $\mathrm{FH}$ diseases at $\mathrm{p}<0.000$ when compared with control group. And no significant difference between (male and female) patients with hypercholesterolemia and $\mathrm{FH}$,

On the other hand the results show significant decrease in vitamin (A,C,E) levels for patients (male and female) with hypercholesterolemia and $\mathrm{FH}$ when compared with control group, the results for vitamins A show significant decrease at $\mathrm{p}<0.05$ for male with (hypercholesterolemia and $\mathrm{FH}$ ) also significant decrease at $\mathrm{p}<0.05$ for females with hypercholesterolemia as well as significant decrease at $\mathrm{p}<0.01$ for female with $\mathrm{FH}$ when compared with control group, and no significant difference between male and female . In addition to the significant decrease in vitamin E level which the results explained significant decrease at $\mathrm{p}<0.001$ for male with (hypercholesterolemia and $\mathrm{FH}$ ) an female with $\mathrm{FH}$ when compared with control group, also significant decrease for females at $\mathrm{p}<0.01$ with hypercholesterolemia, but significant increase at $\mathrm{p}<0.05$ for female with hypercholesterolemia when compared with male while no significant difference for FH patients when compared between male and female. The results for vitamin $\mathrm{C}$ level explained significant decrease at $\mathrm{p}<0.01$ for (male and female) with hypercholesterolemia and male with $\mathrm{FH}$ as well as female 
with FH significant decrease at $\mathrm{p}<0.001$ when compared with control group, the results show significant decrease in females with (hypercholesterolemia and $\mathrm{FH})$ at $(\mathrm{p}<0.05$ and $\mathrm{p}<0.01)$ respectively. When compared with male with (hypercholesterolemia and $\mathrm{FH}$ ) diseases.

As well as the results for Hcy level show significant increase at $\mathrm{p}<0.001$ and $\mathrm{p}<0.000$ for hypercholesterolemia and FH (male) respectively. Other side the results indicated high significant at $\mathrm{p}<0.001$ and $\mathrm{p}<0.000$ for hypercholesterolemia and $\mathrm{FH}$ (female) respectively when compared with control group. The results show significant increase at $p<0.05$ and at $p<0.01$ for hypercholesterolemia and FH (female) when compared with male patients

On the other side the genetic study polymorphisms for MTHFR gene and role of MTHFR in the development hypercholesterolemia and risk CHD reduces GSH level, the MTHFR enzyme activity is associated with the mutations within the MTHFR gene, in this study used 2 samples with FH and hypercholesterolemia the samples successfully amplify using PCR, the following figure (1) are gel electrophoresis pictures for PCR reaction.

Analyzing the sequencing results of 2 samples for exon 4 , sequence results were analyzed using the DNA sequencing analysis software V1.4.0 from Geopiza to identify variants in sequences $<$ we first manually compared results to the reference sequences (NM005957) obtained from UCSC genome browser, then used finch1.4.0 software (www.geospia.com) to cross check ,

In patients studies, 2samples of MTHFR gene exon4. Where analyzing the sequencing and obtained the DNA sequence from NCBI website and compare the resulting DNA sequences of patient samples (Query sequence) with the reference sequence. however, found 2 mutation in the sequence of our target region after comparing with the reference sequence, the results show in exon4, Pro (777) deletion (C) and Glu (784) deletion (A) in patient 1 (female with hypercholesterolemia), Lys (10844) deletion (G) and Asp (10877) in patient2 ( female with FH) which leading frame shift or protein truncation . 


\section{DISCUSSION}

The result on table 2 show significant decrease in resistin level for the male group with hypercholesterolemia may be the effect of drugs such as pitavastatin which can regulate the level with resistin, together with the level of other inflammatory cytokines and adipocytokines. This is consistent with [Ohbayashi 2008] (27). On other side significant increase for female group in resistin level some studied show the resistin level have been reported to be markedly elevated in obese mice. and to be decrease by insulin sensitizers and by administration of antiresistin antiserum (28), however resistin association with inflammatory markers appear to be independent of BMI suggest that resistin may have a direct pro inflammatory role or mediate its effects via yet to be discovered obesity independent mechanisms $(29,30)$. Resistin expression in adiposetissue adipocytes and macrophages is increased in obesity, leading to increased circulating resistin levels. There are also strong positive correlations between plasma resistin levels and increases in body mass index (BMI) and visceral fat (31).and The relationship between BMI and risk of CVD is well established in some studies (32), BMI is positively associated with serum cholesterol level in middle-age men and the changing in cholesterol levels over the six-year follow-up was significantly related to the changing in BMI. Alterations in lipid and lipoprotein concentrations and changing the CVD risk factors agree with some studies (33). The association between hypercholesterolemia and BMI in men and women was not the same. In early middleage the risk of hypercholesterolemia in obese people was more than overweight people while in older age this relation was increased in overweight men without significant differences in women.

The association between serum cholesterol levels and BMI based on age and gender was reported in other studies. Serum cholesterol level increased with age BMI. Alteration in serum cholesterol levels was related to lifestyle factors in some areas (34). the effects of changing body 
weight on plasma cholesterol concentrations may also vary with level of adiposity, as some studies suggest greater increases with weight gain among nonobese than obese men and women. one of the studies suggest changes in adiposity as measured by BMI and waist circumference to the odds of becoming hypercholesterolemic among a vigorously active and generally lean population of men and women in whom the risk of developing high cholesterol may appear remote. Several simple combinations of the baseline and follow-up BMI are used to characterize their relationship to incident high cholesterol. The results for the study are consistent with the hypothesis that weight gain acutely increases the risk of hypercholesterolemia (35).

On the other hand significant increase in ox-LDL for (male and female) with hypercholesterolemia it is now widely accepted that oxidative modification of low density lipoproteins (LDL) convert these native particles into pathogenic, immunogenic and atherogenic particles. Current clinical research addresses the oxidation of LDL as a causative and initiating event in many pathological conditions and the oxidative modification of LDL enhances its atherogenicity. The chemical composition of LDL makes these particles susceptible to oxidation by different lipid oxidants. The polyunsaturated acyl chains of cholesterol esters, phospholipids and triglycerides are vulnerable to oxidation, as is the sterol of free cholesterol and cholesterol esters (36). Important role in process of atherosclerosis plays oxidative stress, especially oxidative modification of LDL cholesterol. Oxidative stress is an imbalance between prooxidatively acting compounds and antioxidants in favour of pro-oxidants causing the damage of important biomolecules. It can directly evoke development of a disease. Oxidative stress participates in pathogenesis of atherogenesis through oxidative damage to lipids in the process of lipoperoxidation. The initiation phase of lipoperoxidation proceeds very slowly depending on concentration of lipophilic antioxidants in LDL, especially $\alpha$-tocopherol, $\gamma$-tocopherol and carotenoids, which protect cells against damage induced by oxidative stress (4). 
Aside from the results show significant decrease on ox-LDL-C (for female and male) with FH the reason may be due Statins, 3-hydroxy-3-methyl glutaryl coenzyme A reductase inhibitors, are known to reduce LDL-C concentrations. Atorvastatin is one of the most widely used statins in the primary and secondary prevention of CVD. The benefit of statin therapy is related not only to its lipid-lowering but also its anti-inflammatory and antioxidant properties (leading to enhanced endothelial function and reduced plaque burden). These pleiotropic effects that are independent of LDL-C-lowering action have drawn recently special attention (37).

On the other hand the results show significant increase in LDL-C for male with hypercholesterolemia and female with $\mathrm{FH}$ also the results indicates significant decrease in HDL$\mathrm{C}$ for (female and male) with (hypercholesterolemia and FH), many epidemiologic data suggest that hypercholesterolemia is the main contributor for atherogenesis, several studies have suggested that hypercholesterolemia is associated with lifestyle habits, like dietary, smoking and physical inactivity status. Despite these considerations, the management of blood lipids levels is difficult, especially in older adults. The effect of abnormal blood lipids levels on cardiovascular system is enhanced with increased age (38).

The results show significant increase in $\mathrm{TC}$ for (female and male) with (hypercholesterolemia and FH) high level of blood cholesterol is usually associated with an increased risk for the development and progression of coronary artery disease and consequently of ischemic heart disease (39) .patients with FH have elevated low-density lipoprotein (LDL) cholesterol levels leading to coronary heart disease(CHD) early in life, The risk of CHD is very high in patients with familial hypercholesterolaemia mainly because of high total and LDL cholesterol plasma levels. Furthermore, familial hypercholesterolaemia is often associated with decreased HDL cholesterol levels (40). The effect of FH on HDL metabolism remains poorly documented. Kinetic studies suggested both increased fractional catabolic rate and decreased 
absolute production rate of HDL-apoA-I. And they suggests that homozygote familial hypercholesterolaemia patients have even lower HDL cholesterol levels than familial hypercholesterolaemia heterozygotes with the same mutation (40).

Familial hypercholesterolaemic patients may be influenced by other risk factors, such as age, male sex, smoking, visceral obesity, high total cholesterol levels, low HDL cholesterol levels, and high lipoprotein(a( levels. These findings underline the importance of plasma HDL cholesterol values, and probably reverse cholesterol transport, as coronary risk factors in familial hypercholesterolaemic patients. In the general population, several epidemiological studies have demonstrated the importance of low HDL cholesterol plasma levels as an independent coronary risk factor. In conclusion, in familial hypercholesterolaemic subjects with similar clinical and genetic factors that could influence coronary heart disease risk, plasma HDL cholesterol values and total/HDL cholesterol ratios are two important coronary risk factors. Hence, treatment of FH should not only focus on lowering total and LDL cholesterol levels, but also on increasing HDL cholesterol for the prevention of coronary heart disease in this high risk group. More prospective and intervention trials should be conducted to establish the relationship between HDL cholesterol levels and coronary heart disease in familial hypercholesterolaemia $(41,42)$.

The results show highly signification in MDA the reason may be due to evolution of hypercholesterolemia is associated with endothelial cell dysfunction (43). Additionally, reports have shown a near-complete abrogation in vascular nitric oxide (NO) bioavailability, elevated oxidant stress, and the creation of a strongly pro-inflammatory condition; symptoms which can culminate in profound impairments to vascular reactivity. Investigation into vascular consequences of chronic hypercholesterolemia, the mechanisms through which these consequences occur, and the potentially beneficial effects of ameliorative therapies have received considerable attention in recent years. Excess oxidative stress is caused by an imbalance between 
pro and anti-oxidant enzymes, leading to an overproduction of free radicals, including superoxide, hydroxyl radicals, and lipid radicals, which may damage cellular components (44).

Some studies show the reason for female with FH that Oxidative stress is known to be a component of molecular and cellular tissue damage mechanisms in a wide spectrum of human diseases (45). A lot of oxygenated compounds, particularly aldehydes such as MDA (MDA) and conjugated dienes, are produced during the attack of free radicals to membrane lipoproteins and polyunsaturated fatty acids. Enzymic superoxide dismutase (SOD) and GSH peroxidase (GSHPx) and nonenzymic antioxidants play an important role in alleviating tissue damage due to the formation of free radicals. A lot of studies have found that serum MDA are higher in subjects with hyperlipidemia and decrease following dietary supplementation with antioxidants. Similar observations have been reported in animal models of hyperlipidemia (46).

The elevated concentrations of MDA, an end product of polyunsaturated fatty acid peroxidation, had present in higher lipid group. This suggests that ROS may already have exerted their cytotoxic effects in this early clinical stage of the disease. Some studies regarding oxidative/antioxidative status at different stages of hyperlipidemia, which represented by varying levels of blood lipid level, have been previously published. Furthermore, MDA levels continued to rise over the course of the disease, indicating overproduction of free radicals and leading to lipid peroxidation and cell oxidative injury, which is considered by some authors to be related to the development of hyperlipidemia complications. Further hypercholesterolemia was associated with oxidative modification of LDL, protein glycation, glucose-autooxidation, thus leading to excess production of lipid peroxidation products which may cause elevation of oxidative stress in higher lipid and hyperlipidemic subjects (47).

These alterations in the levels of serum lipid peroxide and antioxidant status in subjects with higher serum TC, LDL-C, and lower HDL-C levels may increase the susceptibility of LDL 
to oxidation in the circulation. As a lipid peroxidation process leading to increased atherogenity of LDL, it follows that antioxidant status should have a major impact not only on the rate of LDL oxidation but perhaps on development of atherosclerosis. It is possible that a potential risk of atherosclerosis in higher lipid group was associated with LDL oxidation as a result of increased levels of LDL-C and decreased antioxidant (48).

The results explained significant decrease in GSH for both (male and female) with (hypercholesterolemia and FH), endogenous non-enzymatic defense system against oxidative stress is including the sulphadryl containing peptide namely GSH. It is widely distributed in all biological tissues. GSH inhibits ROS oxidative injuries directly via its sulfhydryl group and indirectly as a cofactor or a coenzyme in ROS enzymatic detoxification process (49).

GSH can be directly oxidized by ROS and RNS or indirectly during GSH dependent peroxidase-catalyzed reactions. Conjugation with endogenous and exogenous electrophiles consumes a substantial portion of cellular GSH (50). GSH plays an important role in the antioxidant defense system, in the metabolism of various nutrients and in the regulation of cellular events including DNA damage, gene expression and apoptosis where its deficiency contributes to oxidative stress. However, these effects of GSH on the mechanisms of lipid and protein oxidation need to be better elucidated (17).

On the other hand the results show significant decrease in vitamin (A,C,E) level for both (male and female) with both (hypercholesterolemia and $\mathrm{FH}$ ), as well as the results show significant increase for both (male and female) with both (hypercholesterolemia and FH) the reason may be Elevated levels of homocysteine are an independent risk factor for cardiovascular diseases. Homocysteine may contribute to enhanced oxidative inactivation of nitric oxide by its redox activity, which arises from the formation of disulfides and the generation of hydrogen peroxide and superoxide anion (51). Elevated Hcy level has been shown to be a risk factor for 
myocardial infarction and stroke. Some limited studies showed that elevated Hcy may increase the risk of retinal vascular diseases such as retinal artery and retinal vein thrombosis and occlusion. Hcy induced vascular problems may be multifactorial, including direct Hcy damage to the endothelium, enhanced LDL peroxidation, and increased platelet aggregation by the effects on the coagulation system (52). Recently, homocysteine has been employed successfully as an independent predictor of atherosclerotic events and of carotid intimal-medial thickness in hyperlipidemic subjects. Several clinical studies also suggest that a high homocysteine level increases the risk of heart attack in children with familial hypercholesterolemia. An elevated homocysteine level is also found to interact strongly with hypertension and smoking as well as with hypercholesterolemia. The combined effect is manifested in both sexes, but appears to be more pronounced in women. The interactive effect with conventional risk factors, especially with smoking and hypertension, suggests that homocysteine may further enhance the cardiovascular risk in these patients (53).

GSH level connected with enzyme MTHFR which have an important role in homocysteine metabolism by catalyzing the conversion of 5, 10-methylene tertrahydrofolate to 5-methylene tertrahydrofolate, and the methyl-group donor in the B12-dependent remethylation of homocysteine to methionine. The Study proves that severe deficiency of the MTHFR enzyme advance to homocystinuria which is a rare inborn error of metabolism symbolizes by highly increased blood and urine homocysteine concentrations. Thus the reduction in MTHFR level promotes to hyperhomocysteinemia, Represent by increased plasma total homocysteine (Hcy) levels, and is frequently observed in patients with vascular diseases (54).

Some studies shows the importance of the homocysteine-dependent transsulfuration pathway in the maintenance of the intracellular GSH pool, and the regulation of this pathway under oxidative stress conditions (55). Studies with purified mammalian methionine synthase and 
cystathionine beta-synthase have revealed the oxidative sensitivity of both junction enzymes, suggesting the hypothesis that redox regulation of this pathway may be physiologically significant. GSH appears to have marked antioxidant activities and therefore may prevent cardiovascular disease. It was suggested that reduced plasma GSH level is a risk factor for development of cardiovascular and cerebrovascular diseases (56).

Homocysteine is metabolized through two main pathways: Remethylation to methionine or transsulfuration to cystathionine and then to cysteine. A decrease in the rate of remethylation of homocysteine into methionine produces hyperhomocysteinemia. It is recognized that hyperhomocysteinemia produces thrombogenesis, vasodilation and endothelial damage and is associated with cardiovascular and cerebrovascular diseases (57) .experimental evidence suggests that homocysteine may promote atherogenesis through its toxic effects on the vascular endothelium, which is likely mediated through oxidative stress (58). Folic acid, alone or combined with other B vitamins, is safe and effective in lowering plasma homocysteine levels. Moreover, antioxidant vitamins, such as vitamins $\mathrm{C}$ and $\mathrm{E}$, may have an adjunctive role in preventing homocysteine-mediated oxidative vascular injury. Observational studies suggest that B vitamins may reduce cardiovascular risk (58).

The inability of the MTHFR enzyme to catalyse the conversion of 5, 10methylenetetrahydrofolate to 5-methyltetrahydrofolate leads to the rise of plasma homocysteine levels in the homozygous mutated subjects. Studies have shown that the level of homocysteinaemia could be normalised by folic acid and vitamin B12 supplementation. Polymorphism of the MTHFR gene at position $677 \mathrm{C}>\mathrm{T}$ may affect its role in the metabolism of homocysteine $(59,60)$.

One possible explanation was that absolute concentrations of lipid-soluble vitamins such as $\alpha$-tocopherol and $\beta$-carotene correlate with lipids and hyperlipidemia is commonly associated 
with increased levels of these vitamins. However, their concentrations may be lower than control levels if adjusted for total lipids [cholesterol plus triglycerides] (48).

Vitamin-C or ascorbic acid is a well-known, powerful and water-soluble antioxidant. It is endogenously present in the cellular cytosol. Vitamin-C antioxidant activity is through donation of electron to the harmful free radicals generated during the oxidative stress process. Ascorbic acid is the most predominant form of vitamin-C in the human body. It prevents oxidative injury in several organs via quenching the injurious free radicals and ROS produced in biological processes. Several beneficial properties for the body have been associated with flavonoids use. Thus, the current study was designed to compare the protective effects of the well-known antioxidants, and $\mathrm{C}$, against hypercholesterolemia induced hepatic oxidative stress in female Wistar albino rats (49).

A 5, 10- Methylenetetrahydrofolate reductase (MTHFR) is one of the main regulatory enzymes of Hcy metabolism that catalyses the reduction of 5, 10-methylenetetrahydrofolate to 5methyltetrahydrofolate, the methyl donor for the remethylation of Hcy to methionine. A common 677CRT transition in the MTHFR gene is a well-established genetic determinant of hyperhomocysteinaemia, and results in a thermolabile protein, with a decreased enzymatic activity $(61)$ and these agree with $(62,63)$ which converts an alanine to a valine codon in the Nterminal catalytic domain of the protein. The association between this MTHFR genotype and the total Hcy (tHcy) circulating levels is well known to be contingent on folate status.

Abbreviation: FH: familial hypercholesterolemia, MDA: Malondialdehyde, GSH: Glutathione, MTHFR: Methylenetetrahydrofolate reductase, Hcy: Homocysteine 


\section{REFERENCES}

1. Pirinccioglu AG, Gökalp D, Pirinccioglu M, Kizil G, Kizil M. Malondialdehyde (MDA) and protein carbonyl (PCO) levels as biomarkers of oxidative stress in subjects with familial hypercholesterolemia. Clin Biochem 2010; 43: 1220-4.

2. Steinbrecher UP, Zhang HF, Lougheed M. Role of oxidatively modified LDL in atherosclerosis. Free Radic. Biol. Med 1990; 9:155-68.

3. Harrison D, Griendling KK, Landmesser U, Hornig B, Drexler H. Role of oxidative stress in atherosclerosis. Am. J Cardiol2003; 91: 7A-11A.

4. Ondrejovicova I, Muchova J, Mislanova C, Nagyova Z, Durackova Z. Hypercholesterolemia, oxidative stress and gender dependence in children. Prague Medical Report2010; 111: 300-12.

5. Widmaier E, Raff H, Strang K. Vander's Human physiology: the mechanisms of body function. $13^{\text {th }}$ ed. New York: McGraw-Hill Science/Engineering/Math 2013.

6. Kashyap ML. Cholesterol and atherosclerosis: a contemporary perspective. Ann Acad Med Singapore1997; 26: 517-23.

7. AL-Suhaimi EA, and Shehzad A. Leptin, resistin and visfatin: the missing link between endocrine metabolic disorders and immunity. European Journal of Medical Research 2013; 18: $1-13$.

8. Musumecil M, Pappalardo F, Tonolo GC, Torrisi F, Gullo F, Musumeci S. Effect of LDL-apheresis on plasma lipids, chitotriosidase and anti-oxLDL antibodies in heterozygous FH. J. Biomedical Science and Engineering 2009; 2: 499-505.

9. Haider L, Fischer MT, Frischer JM, Bauer J, et al. Oxidative damage in multiple sclerosis lesions. Brain 2011; 134: 1914-24. 
10. Miller E, Mrowicka M, Malinowska K, Mrowicki J, et al. Effects of whole-body cryotherapy on a total antioxidative status and activities of antioxidative enzymes in blood of depressive multiple sclerosis patients. World J Biol Psychiatry 2011; 12: 223-7.

11. Acar AM. Cevik MU, Evliyaoglu O, Ertugrul Uzar E, Tamam Y, et al. Evaluation of serum oxidant/antioxidant balance in multiple sclerosis. Acta Neurol Belg 2012; 1-6.

12. Owen JB, Butterfield DA. Measurement of oxidized/reduced GSH ratio. Methods Mol Biol 2010; 648: 269-77.

13. Kawashiri M, Kajinami K, Nohara A, Yagi K, Inazu A, Kaizumi J, Mabuchi H. Effect of common methylenetetrahydrofolate reductase gene mutation on coronary artery disease in familial hypercholesterolemia. Am J Cardiol 2000; 86: 840-5.

14. Mudd SH, Uhlendorf BW, Freeman JM, Finkelstein DJ, Shih VE. Homocystinuria associated with decreased MTHFR activity. Academic Press. Inc.1972; 46: 905-12.

15. Alam MA. Methylenetetrahydrofolate reductase gene polymorphisms and cardiovascular diseases. Cell Dev Biol 2016; 5: 2.

16. Miranda-Vilela AL, and Lordelo GS. Role of MTHFR (MTHFR) GSH S-transferases (Gstm1 and T1) and haptoglobin (Hp) gene polymorphisms in susceptibility to chronic myeloid leukemia (Cml). J Hematol Thromb Dis 2013; 1: 1-16.

17. Shallal SS. Immunochemical and genetics study on Iraqi women with recurrent abortion. M.Sc. Thesis, College of Science, University of Baghdad-Iraq 2013.

18. Gokcen C, Kocak N, Pekgor A. MTHFR gene polymorphisms in children with attention deficit hyperactivity disorder. Int J Med Sci 2011; 8: 523-8.

19. Uchiyama M, Mihara M. Determination of malonaldehyde precursor in tissues by thiobarbituric acid test. Anal Biochem.1978; 34: 271-8. 
20. Fairbanks V, Klee GG. Biochemical aspects of hematology. In: N.W. Tietz Editor .Textbook of clinical chemistry W.B. Saunders, Philadelphia 1986; 1532-4.

21. Varley H .Practical clinical biochemistry. $4^{\text {th }}$ ed. The white friars press limited, London and Tonbridge, Great Britain 1967.

22. Colowick SP, Kaplan NO. Methods in enzymology. Vol. 62, part D, Academic press, USA 1979; p.7

23. Varly H, Gowenlock AH, Bell M. Practical clinical biochemistry. $5^{\text {th }}$ ed., Vol. 2, Harold Varly, Great Britian 1976.

24. Wootton LDP. Micro analysis in medical biochemistry. $5^{\text {th }}$ ed., J. and A Churchill LTD, group limited, London 1974.

25. Rinaldi C, Anglo R, Ruggeri A, Calabro M et al. PON1 gene polymorphisms Cancer: A case-control study in a population from southern Italy. J. Mol. Biomarker and Diagnosis 2014; 5: 2-6.

26. Sambrook J, and Russell D. Invitro application of DNA by the PCR in molecular cloning; a laboratory manual. $3^{\text {rd }}$ ed. Cold Spring Harbor Laboratory Press 2001; 691.

27. Ohbayashi H. Pitavastatin improves serum resistin levels in patients with hyperchole sterolemia. J. Atheroscler Thromb.2008; 15: 87-93.

28. Steppan CM, Bailey ST, Bhat S, Brown EJ, Banerjee RR, Wright CM. The hormone resistin links obesity to diabetes. Nature2001; 409: 307-12.

29. Shetty GK, Economides PA, Horton ES, Mantzoros CS, Veves A. Circulating adiponectin and resistin levels in relation to metabolic factors, inflammatory markers, and vascular reactivity in diabetic patients and subjects at risk for diabetes. Diabetes Care 2004; 27: $2450-7$. 
30. Mohammadzadeh G, Zarghami N, Mobaseri M. Serum resistin concentration in obese diabetic patients: Any possible relation to insulin resistance indices? Int $\mathrm{J}$ Endocrinol Metab 2008; 4: 183-93.

31. Melone M, Wilsie L, Palyha O, Strack A, Rashid S. Discovery of a new role of human resistin in hepatocyte low-density lipoprotein receptor suppression mediated in part by proprotein convertase subtilisin/kexin type 9. J Am Coll. Cardiol 2012; 59: 1697-705.

32. Wattanakit K, Lutsey PL, Bell EJ, Gornik H, Cushman M, Heckbert SR et al. Association between cardiovascular disease risk factors and occurrence of venous thromboembolism. A timedependent analysis. Thromb Haemost 2012; 108: 508-15.

33. Labreuche J, Touboul PJ, Amarenco P. Plasma triglyceride levels and risk of stroke and carotid atherosclerosis: a systematic review of the epidemiological studies. Atherosclerosis 2009; 203: 331-45.

34. Veghari G, Sedaghat M, Joshghani H, Banihashem S et al. Obesity and risk of hypercholesterolemia in Iranian northern adults. ARYA Atheroscler 2013; 9: 2-6.

35. Williams PT. Changes in body weight and waist circumference affect incident hypercholesterolemia during 7 years of follow-up. Obesity (Silver Spring) 2013; 16: $2163-8$

36. Nour-Eldin EM, Almarzouk A, Assiri AM, Elsheikh OM, Mohamed BEA, and Babakr AT. Oxidized low density lipoprotein and total antioxidant capacity in type- 2 diabetic and impaired glucose tolerance Saudi men. Diabetology \& Metabolic Syndrome 2014; 94: 110.

37. Kotani K, Yamada T, Miyamoto M, Ishibashi S, Taniguchi N, Gugliucci A. Influence of atorvastatin on serum amyloid A-low density lipoprotein complex in hypercholesterolemic patients. Pharmacological Reports 2012; 64: 212-6. 
38. Ahmed AM, Rhmtallah AA, and Eledum HY. Relationship between hypercholesterolemia, and age, gender and body mass index. Res J Pharmaceutical, Biological and Chemical Sciences 2014; 5: 1137-41.

39. El-Shafey MM, and Abd-Ellah MF. Hesperidin improves lipid profile and attenuates oxidative stress in hypercholesterolemic rats. Int J Pharma Sci2014; 4: 554-9.

40. Miltiadous G, Marios A. Cariolou MA and Elisaf M. HDL cholesterol levels in patients with molecularly defined FH. Annals Clin Laborat Sci 2002; 32: 50-4.

41. Real JT, Chaves FJ, Martinez-Uso I, GarcIa-Garcia AB, et al. Importance of HDL cholesterol levels and the total/HDL cholesterol ratio as a risk factor for coronary heart disease in molecularly defined heterozygous familial hypercholesterolaemia. Eur Heart $\mathbf{J}$ 2001; 22: 465-71.

42. Hamoud S, Kaplan M, Meilin E, Hassan A, Torgovicky R, Cohen R, Hayek T. Niacin administration significantly reduces oxidative stress in patients with hypercholesterolemia and low levels of high-density lipoprotein cholesterol. Am J Med Sci 2013; 345: 195-9.

43. Stapleton PA, Goodwill AG, James ME, Frisbee JC. Altered mechanisms of endotheliumdependent dilation in skeletal muscle arterioles with genetic hypercholesterolemia. Am J Physiol Regul Integr Comp Physiol 2007; 293: R1110-9.

44. Stapleton PA, Goodwill AG, James ME, Brock RW, Frisbee JC. Hypercholesterolemia and microvascular dysfunction: interventional strategies. J Inflammation 2010; 754: 1-10.

45. Valko M, Leibfritz D, Moncol J, Cronin MT, Mazur M, Telser J. Free radicals and antioxidants in normal physiological functions and human disease. Int. J. Biochem. Cell Bi.2007; 39: 44-84. 
46. Yang R, Le G., Li A, Zheng J, Shi Y. Effect of antioxidant capacity on blood lipid metabolism and lipoprotein lipase activity of rats fed a high-fat diet. Nutrition 2006; 2: $1185-91$.

47. Stocker R. and Keaney JF. Role of oxidative modificationsin atherosclerosis. Physiol Rev 2004; 84: 1381-478.

48. Yang R, Shi YH, Hao G, Li W, and Guo-Wei LG. Increasing oxidative stress with progressive hyperlipidemia in human: Relation between MDA and Atherogenic Index $\mathbf{J}$ Clin Biochem Nutr 2008; 43: 154-8.

49. Alkhamees OA. Protective effects of vitamin-P and vitamin-C on hypercholesterolemiainduced oxidative hepatic damage and lipid profile changes in female rats: A comparative study. J Applied Pharmaceutical Sci 2013; 3: 099-105.

50. Lushchak VL. GSH homeostasis and functions: potential targets for medical intervention. J Amino Acids 2012; 2012: 1-26.

51. Ciftci GA, Ertorun I, Akalin A, Alatas IO, Musmul A. The effects of atorvastatin on antioxidant /antiinflammatory properties of HDLs in hypercholesterolemics. Turk J Med Sci 2015; 45: 345-51.

52. Er H, Evereklioglu C, Cumurcu T, Turkoz Y, Ozerol E, Ahin KS, Doganay S. Serum homocysteine level is increased and correlated with endothelin-1 and nitric oxide in Behcet's disease. Br J Ophthalmol 2002; 86: 653-7.

53. Choy PC, Mymin D, Zhu Q, Dakshinamurti K, Karmin O. Atherosclerosis risk factors: The possible role of homocysteine. Molecular and Cellular Biochemistry 2000; 207: 1438. 
54. Li Z, Yadav U, Mahemuti A, Tang BP, Upur H. Association of MTHFR genetic polymorphisms with venous thromboembolism in Uyghur population in Xinjiang, China. Int J Clin Exp Med 2015; 8: 17703-11.

55. Mosharov EL, Cranford MR, Banerjee R. The quantitatively important relationship between homocysteine metabolism and GSH synthesis by the transsulfuration pathway and its regulation by redox changes. Biochemistry 2000; 39: 13005-11.

56. Megahed MA, Hassanin KMA, Ibrahim M. I. Youssef IM, Elfghi ABA, Amin KA. Alterations in plasma lipids, GSH and homocysteine in relation to dietary copper in rats. J Investigational Biochemistry 2013; 1:21-5.

57. Peter K, Lip GY. Thrombosis and cardiovascular disease: Exciting perspectives in cardiovascular prevention and therapy. Thromb Haemost 2010; 103: 875-6.

58. Title LM, Cummings PM, Giddens K, Genest JJ, Nassar BA. Effect of folic acid and antioxidant vitamins on endothelial dysfunction in patients with coronary artery disease. $\mathrm{J}$ Am College Cardiol 2000; 36: 758-75.

59. Liew SC, Gupta ED. Methylenetetrahydrofolate reductase (MTHFR) C677T polymorphism: Epidemiology, metabolism and the associated diseases. European Journal of Medical Genetics 2015; 58: 1-10.

60. Verhoef P, Rimm E, Hunter DJ, Chen J, Willett WC, Kelsey K, Stampfer MJ. A common mutation in the Methylenetetrahydrofolate reductase gene and risk of coronary heart disease: results among U.S. men. JACC 1998; 32: 353-9.

61. Castro R, Rivera I, Ravasco P, Camilo ME, Jakobs C, Blom HJ, Almeida IT. 5, 10MTHFR (MTHFR) 677CRT and 1298ARC mutations are associated with DNA hypomethylation. J Med Genet 2004; 41: 454-8. 
62. Frosst P, Blom HJ, Milos R, Goyette P, Sheppard CA et al. candidate genetic risk factor for vascular disease: a common mutation in MTHFR. Nat Genet 1995; 10: 111-3.

63. Klerk M, Verhoef P, Clarke R, Blom HJ, Kok FJ, Schouten EG. MTHFR Studies Collaboration Group. MTHFR 677CRT polymorphism and risk of coronary heart disease: a meta-analysis. JAMA 2002; 288: 2023-31. 
Table 1: sequence of the primers used for exon amplification of the MTHFR gene

\begin{tabular}{lllllll}
\hline $\begin{array}{l}\text { Primer } \\
\text { name }\end{array}$ & Primer sequence & $\begin{array}{l}\text { Primer } \\
\text { length } \\
\text { (bp) }\end{array}$ & Tm & GC\% & $\begin{array}{l}\text { Product } \\
\text { length } \\
\text { (bp) }\end{array}$ & $\begin{array}{l}\text { Exon } \\
\text { length } \\
\text { (bp) }\end{array}$ \\
\hline $\begin{array}{l}\text { MTHFR } \\
\text { Exon 4 } \\
\text { forward }\end{array}$ & $\begin{array}{l}\text { 5'- } \\
\text { GTGACCAGTGGGAAGAGGA }\end{array}$ & 20 & 59.39 & 60.00 & 102 & 111 \\
$\begin{array}{l}\text { MTHFR } \\
\text { Exon 4 } \\
\text { reverse }\end{array}$ & $\begin{array}{l}\text { 5'- } \\
\text { CTGCCACACAGATGTCAAAG }\end{array}$ & 20 & 57.02 & 50.00 & 102 & 111 \\
\hline
\end{tabular}

Table 2: Resistin and some biochemical parameters

\begin{tabular}{|c|c|c|c|c|c|c|}
\hline Patients & $\begin{array}{l}\text { Resistin } \\
\mathrm{ng} / \mathrm{ml}\end{array}$ & $\begin{array}{l}\text { BMI } \\
\mathrm{kg} / \mathrm{m}^{2}\end{array}$ & $\begin{array}{l}\text { ox-LDL } \\
\text { ng/ml }\end{array}$ & $\begin{array}{l}\text { LDL-C } \\
\mathrm{mmol} / \mathrm{l}\end{array}$ & $\begin{array}{l}\text { HDL-C } \\
\mathrm{mmol} / \mathrm{l}\end{array}$ & $\begin{array}{l}\text { TC } \\
\mathrm{mmol} / \mathrm{l}\end{array}$ \\
\hline Control (male) & $\begin{array}{l}5.54 \pm 1.2 \\
1\end{array}$ & $\begin{array}{l}25.04 \pm 0.0 \\
4\end{array}$ & $\begin{array}{l}21.67 \pm 2.5 \\
1\end{array}$ & $\begin{array}{l}2.78 \pm 0.8 \\
6\end{array}$ & $\begin{array}{l}1.35 \pm 0.03 \\
2\end{array}$ & $\begin{array}{l}4.32 \pm 1.04 \\
1\end{array}$ \\
\hline Control (female) & $\begin{array}{l}5.48 \pm 1.4 \\
0\end{array}$ & $\begin{array}{l}25.09 \pm 0.0 \\
3\end{array}$ & $\begin{array}{l}21.33 \pm 2.6 \\
0\end{array}$ & $\begin{array}{l}2.60 \pm 0.9 \\
0\end{array}$ & $\begin{array}{l}1.55 \pm 0.04 \\
5\end{array}$ & $4.46 \pm 1.06$ \\
\hline $\begin{array}{l}\text { Hypercholesterolem } \\
\text { ia } \\
\text { (male) }\end{array}$ & $\begin{array}{l}4.79 \pm 1.0 \\
9 \\
*\end{array}$ & $\begin{array}{l}30.31 \pm 1.2 \\
5 \\
* * * *\end{array}$ & $\begin{array}{l}41.51 \pm 5.2 \\
6 \\
* * * *\end{array}$ & $\begin{array}{l}3.97 \pm 0.8 \\
6 \\
*\end{array}$ & $\begin{array}{l}0.34 \pm 0.02 \\
3 \\
* *\end{array}$ & $\begin{array}{l}5.43 \pm 1.04 \\
1 \\
*\end{array}$ \\
\hline $\begin{array}{l}\text { Familial } \\
\text { Hypercholesterolem } \\
\text { ia } \\
\text { (male) }\end{array}$ & $\begin{array}{l}5.08 \pm 2.2 \\
1\end{array}$ & $\begin{array}{l}29.04 \pm 2.2 \\
5 \\
* * *\end{array}$ & $\begin{array}{l}20.01 \pm 2.1 \\
3 \\
*\end{array}$ & $\begin{array}{l}3.21 \pm 0.9 \\
7\end{array}$ & $\begin{array}{l}0.71 \pm 0.02 \\
1 \\
*\end{array}$ & $\begin{array}{l}6.41 \pm 0.07 \\
* * *\end{array}$ \\
\hline $\begin{array}{l}\text { Hypercholesterolem } \\
\text { ia } \\
\text { (female) }\end{array}$ & $\begin{array}{l}7.89 \pm 0.9 \\
1 \\
* * * * \\
\# \#\end{array}$ & $\begin{array}{l}32.31 \pm 2.3 \\
1 \\
* * * * \\
\# \#\end{array}$ & $\begin{array}{l}38.71 \pm 2.3 \\
5 \\
* * * \\
\# \#\end{array}$ & $\begin{array}{l}3.65 \pm 0.8 \\
5 \\
*\end{array}$ & $\begin{array}{l}0.75 \pm 0.03 \\
2 \\
* * \\
\#\end{array}$ & $\begin{array}{l}5.84 \pm 1.21 \\
* *\end{array}$ \\
\hline $\begin{array}{l}\text { Familial } \\
\text { Hypercholesterolem } \\
\text { ia } \\
\text { (female) }\end{array}$ & $\begin{array}{l}6.98 \pm 1.3 \\
2 \\
* * \\
\# \#\end{array}$ & $\begin{array}{l}29.35 \pm 2.1 \\
2 \\
* * *\end{array}$ & $\begin{array}{l}20.44 \pm 3.0 \\
3 \\
* \\
\#\end{array}$ & $\begin{array}{l}4.02 \pm 1.0 \\
4 \\
* * \\
\#\end{array}$ & $\begin{array}{l}0.93 \pm 0.02 \\
1 \\
* \\
\#\end{array}$ & $\begin{array}{l}6.88 \pm 1.07 \\
* * * *\end{array}$ \\
\hline
\end{tabular}


Table 3: Lipid peroxidation and some antioxidant

\begin{tabular}{|c|c|c|c|c|c|c|}
\hline Patients & $\begin{array}{l}\text { MDA } \\
\mu \mathrm{mol} / \mathrm{l}\end{array}$ & $\begin{array}{l}\text { GSH } \\
\mu \mathrm{mol} / \mathrm{l}\end{array}$ & $\begin{array}{l}\text { Vit. A } \\
\text { mmol/l }\end{array}$ & $\begin{array}{l}\text { Vit. C } \\
\mathrm{mmol} / \mathrm{l}\end{array}$ & $\begin{array}{l}\text { Vit. E } \\
\mathrm{mmol} / \mathrm{l}\end{array}$ & $\begin{array}{l}\mathrm{HCY} \\
\mathrm{ng} / \mathrm{ml}\end{array}$ \\
\hline Control (male) & $4.66 \pm 0.56$ & $9.59 \pm 0.34$ & $1.37 \pm 0.29$ & $34.67 \pm 6.043$ & $13.49 \pm 3.41$ & $7.82 \pm 1.66$ \\
\hline Control (female) & $4.70 \pm 0.51$ & $8.49 \pm 0.60$ & $1.49 \pm 0.33$ & $33.70 \pm 6.036$ & $12.30 \pm 3.50$ & $7.6 \pm 2.11$ \\
\hline $\begin{array}{l}\text { Hypercholesterolemia } \\
\text { (male) }\end{array}$ & $\begin{array}{l}11.53 \pm 3.04 \\
* * * *\end{array}$ & $\begin{array}{l}5.65 \pm 0.67 \\
* * * *\end{array}$ & $\begin{array}{l}0.63 \pm 0.23 \\
*\end{array}$ & $\begin{array}{l}23.93 \pm 2.23 \\
* *\end{array}$ & $\begin{array}{l}6.21 \pm 2.14 \\
* * * *\end{array}$ & $\begin{array}{l}15.83 \pm 4.44 \\
* * *\end{array}$ \\
\hline $\begin{array}{l}\text { Familial } \\
\text { Hypercholesterolemia } \\
\text { (male) }\end{array}$ & $\begin{array}{l}11.98 \pm 4.28 \\
* * * *\end{array}$ & $\begin{array}{l}4.97 \pm 0.82 \\
* * * *\end{array}$ & $\begin{array}{l}0.62 \pm 0.23 \\
*\end{array}$ & $\begin{array}{l}24.06 \pm 2.16 \\
* *\end{array}$ & $\begin{array}{l}6.05 \pm 2.11 \\
* * * *\end{array}$ & $\begin{array}{l}18.25 \pm 4.2 \\
* * * * \\
\#\end{array}$ \\
\hline $\begin{array}{l}\text { Hypercholesterolemia } \\
\text { (female) }\end{array}$ & $\begin{array}{l}11.47 \pm 2.89 \\
* * * *\end{array}$ & $\begin{array}{l}6.79 \pm 0.87 \\
* * * \\
\#\end{array}$ & $\begin{array}{l}0.72 \pm 0.25 \\
* *\end{array}$ & $\begin{array}{l}22.46 \pm 1.37 \\
* * \\
\#\end{array}$ & $\begin{array}{l}7.37 \pm 2.05 \\
* * * \\
\#\end{array}$ & $\begin{array}{l}13.56 \pm 3.34 \\
* * *\end{array}$ \\
\hline $\begin{array}{l}\text { Familial } \\
\text { Hypercholesterolemia } \\
\text { (female) }\end{array}$ & $\begin{array}{l}10.98 \pm 2.44 \\
* * * * \\
\#\end{array}$ & $\begin{array}{l}5.05 \pm 1.03 \\
* * * *\end{array}$ & $\begin{array}{l}0.51 \pm 0.22 \\
* * *\end{array}$ & $\begin{array}{l}19.95 \pm 1.01 \\
* * * \\
\# \#\end{array}$ & $\begin{array}{l}6.67 \pm 2.10 \\
* * *\end{array}$ & $\begin{array}{l}17.78 \pm 3.90 \\
* * * * \\
\# \#\end{array}$ \\
\hline
\end{tabular}

$* \mathrm{p}<0.05, * * \mathrm{p}<0.01, * * *: \mathrm{p}<0.001, * * * *: \mathrm{p}<0.000$ (when compared with control)

$\# \mathrm{p}<0.05, \# \#: \mathrm{p}<0.01, \# \# \#: \mathrm{p}<0.001, \# \# \# \#: \mathrm{p}<0.000$ (when compared between female and male) 


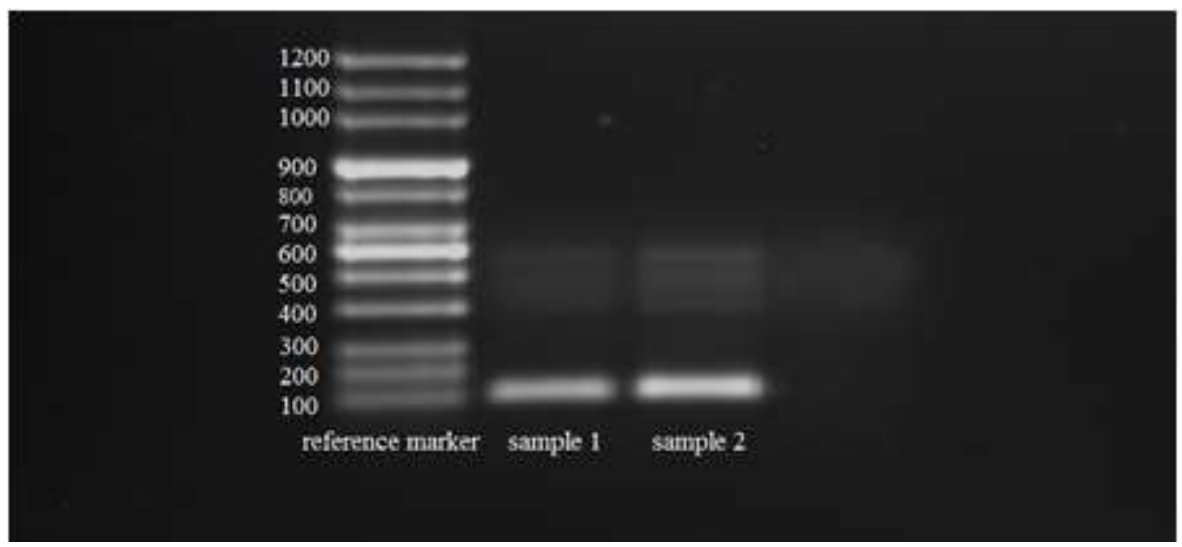

Fig. 1: Electroploregram of the safe stained 2\% agarose gel showing Amplified PCR product of Exon4.

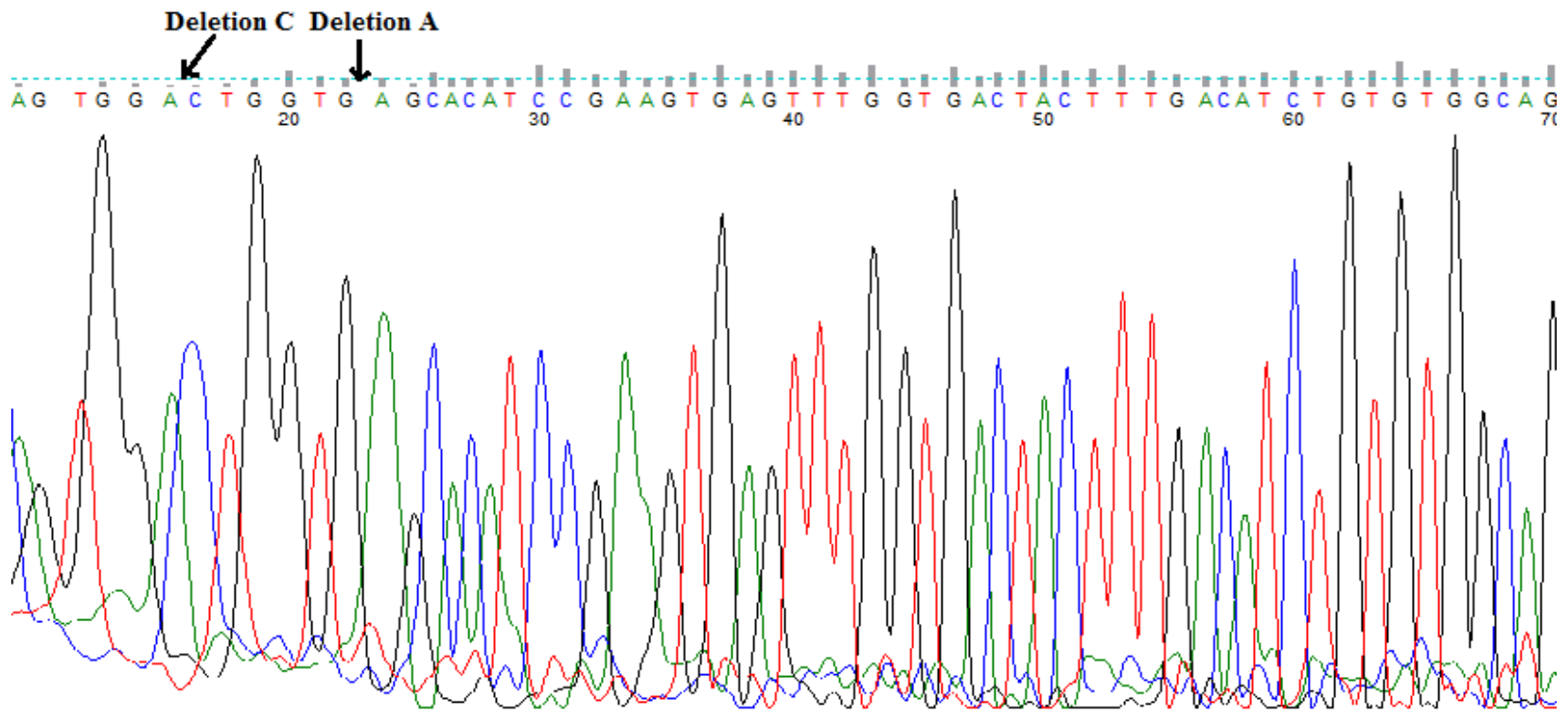

Fig. 2: The sample No.1 (female with hypercholesterolemia) sequence result of MTHFR gene exon4. 

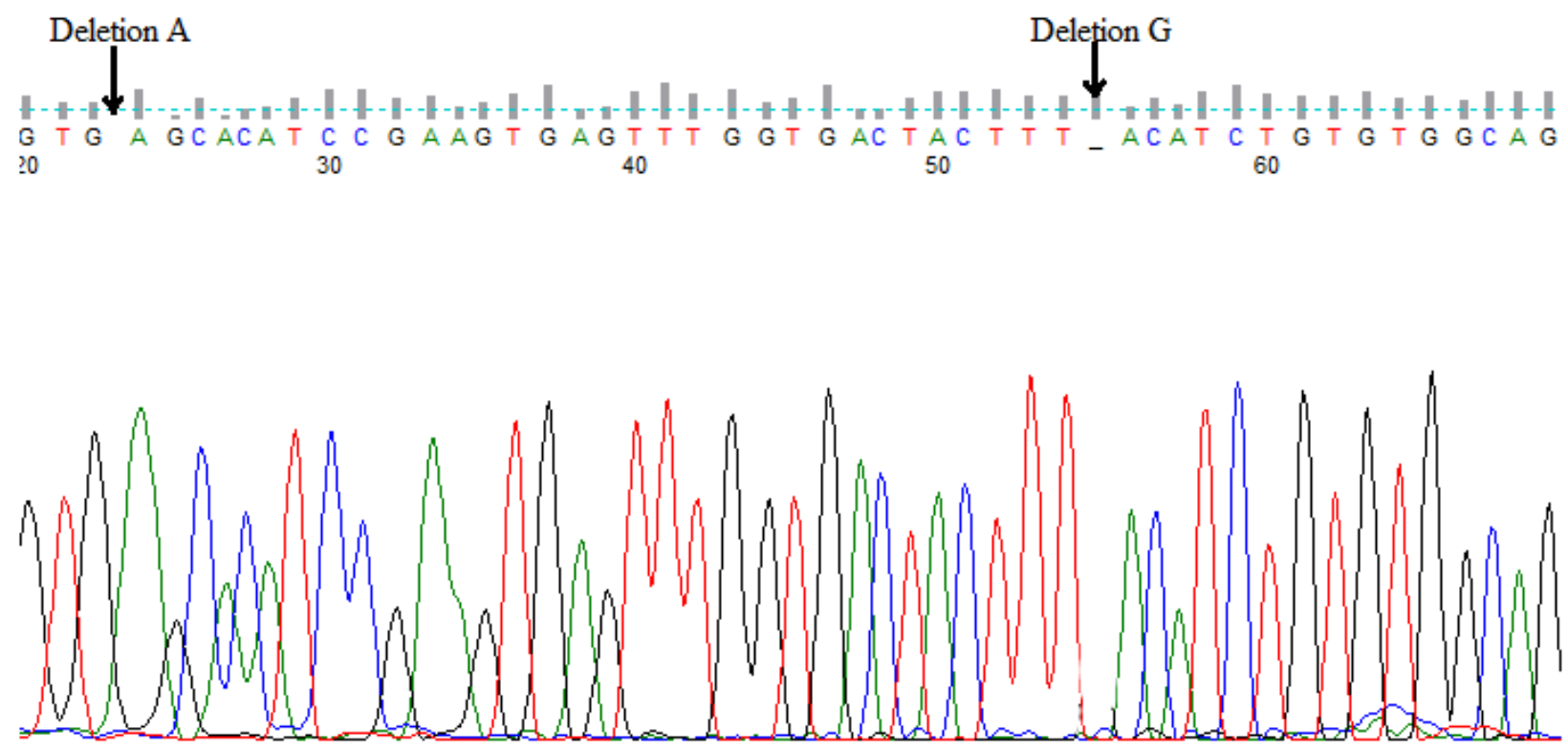

Fig. 3: The sample No.1 (female with FH) sequence result of MTHFR gene exon4. 